\title{
Extraction of Essential Oil from Cinnamon (Cinnamomum zeylanicum)
}

\author{
Y.C.WONG*, M.Y. AHMAD-MUDZAQQIR and W.A. WAN-NURDIYANA \\ Faculty of Agro Based Industry, University Malaysia Kelantan, Jeli Campus, \\ Locked Bag 100, 17600 Jeli, Kelantan, Malaysia. \\ ${ }^{*}$ Corresponding author E-mail: yeeching@umk.edu.my
}

http://dx.doi.org/10.13005/ojc/300105

(Received: December 15, 2013; Accepted: January 02, 2014)

\begin{abstract}
Cinnamomum zeylanicum is one of the herbs and spices plants that come from cinnamon family which contains high quality of essential oil. In this study, the essential oil from plant Cinnamomum zeylanicum was extracted using two methods which were steam distillation and Soxhlex extraction. Steam distillation produced high quality essential oil extraction using separatory funnel. Soxhlet extraction produced essential oil in crude form using rotary evaporator to purify the extracted product. Cinnamon essential oil contains high cinnamaldehyde content which is the main component in cinnamon. The percentage of cinnamaldehyde in essential oil from steam distillation was about $90 \%$ and $62-73 \%$ from Soxhlet extraction. Cinnamon essential oil has high antimicrobial properties which formed clear zone when tested with gram positive bacteria Bacillus subtilis s.p and a gram negative bacterium Escherichia coli. It also showed antimicrobial properties with two unknown bacteria with unknown characteristics. Cinnamaldehyde contains high antibiotic quality since it is the main compound in cinnamon.
\end{abstract}

Key words: Cinnamon, Cinnamomun zeylanicum, Essential oil, Extraction, Antioxidant activity.

\section{INTRODUCTION}

Cinnamomum zeylanicum is one of the oldest herbal medicine known, having been mentioned in Chinese texts since 4000 years ago ${ }^{1}$. Cinnamomum zeylanicum is an evergreen tropical tree, belonging to the Lauraceae family. Cinnamon barks and leaves are widely used as spice and flavoring agent in foods and for various applications in medicine ${ }^{2}$.
Cinnamon is often used for medicinal purposes due to its unique properties. The essential oil from its bark is rich in trans-cinnamaldehyde with antimicrobial effects against animal and plant pathogens, food poisoning and spoilage bacteria and fungi ${ }^{3}$. The bark and leaves of Cinnamomum $s p$ are commonly used as spices in home kitchens and their distilled essential oils are used as flavoring agent in the food and beverage industries ${ }^{1}$. 
The bark of the tree is dried and used for spice. In the United States, cinnamon is used to flavor cereals, grain-based dishes, and fruits. Cinnamon is among the world's most widely used spices and is relatively inexpensive. Cinnamon contains antioxidants and other active ingredients which are found in the water-soluble portions of cinnamon, and not the cinnamon oil. It is through these components that cinnamon is believed to produce its associated health effects ${ }^{4}$.

Until now more than 300 volatiles were found as constituents of essential oils of cinnamon. It has been established that the oils and extracts from cinnamon possess a distinct antioxidant activity, which is especially attributed to the presence of phenolic and polyphenolic substances ${ }^{2}$. Some plant essential oils or their constituents have been proposed as an alternative for the commonly used synthetic pediculicides, because they were exempted from toxicity data requirements. Furthermore, plant essential oils are widely available and some are relatively inexpensive compared to plant extracts ${ }^{1}$.

To extract the essential oil, steam distillation and Soxhlet extraction methods were used. Steam distillation is the simplest method to extract the essential oil from cinnamon. Steam distillation is mostly used to extract various types of essential oils. The process is cheaper than other extraction methods. It does not require any solvent and is safer than other methods. The advantage of steam distillation is that it is relatively cheap to operate at basic level, and the properties of the oils produced by this method are not altered. As steam reduces the boiling point of a particular component of the oil, it never decomposes in this method. Apart from being economical, it is also relatively faster compared to other methods.

Meanwhile, Soxhlet extraction is one of the traditional methods used for the isolation of metabolites from plant material. Analytes with medium to low volatility which may play a role for the aroma and quality of oil extracted from the plant material are extracted with this technique ${ }^{5-7}$. The correct choice of solvent is important in order to obtain a good yield from the extraction as well as to prevent the loss of volatiles. The solvent used in this method is indicative of the polarity of the compounds extracted. The extraction is usually carried out for a long period. The disadvantage of this technique is that, due to the long heating period, the analytes are exposed to high temperatures, which may lead to thermal degradation of some compounds. The recovered sample is diluted and has to be concentrated further, by evaporation. It is during this step that loss of volatiles can take place ${ }^{5-7}$.

In this study, the essential oils obtained from the bark of Cinnamomum zeylanicum (cinnamon) was characterized by analytical TLC and GC/MS, and their antimicrobial and antioxidant compounds were detected by TLC-bio-autography assays. Essential oil of cinnamon bark was found to be a unique aromatic monoterpene-rich natural source, with trans-cinnamaldehyde ${ }^{8}$. For determining the chemical composition of the essential oil, high performance liquid chromatography (HPLC) was used.

The objectives of the research were to extract and compare the two methods for extraction of cinnamon's essential oil, to analyze and identify the active compound in the essential oil and to identify the antimicrobial properties in cinnamon.

\section{EXPERIMENTAL}

Bark of Cinnamomum zeylanicum was obtained from shops. This species is not planted in Malaysia. The material is easy to get since cinnamon is commonly used as spices in Malaysian cooking.

\section{Steam distillation method}

Amount of 100 to $150 \mathrm{~g}$ of mashed cinnamon sticks were introduced into the distillation flask (1L), which was connected to the steam generator via a glass tube and to a condenser to retrieve the oil. The essential oils were volatilized with boiling water at temperature $100^{\circ} \mathrm{C}$ for 5 and 10 hours. The recovered mixture was allowed to settle and the oil was withdrawn ${ }^{9-10}$. After the steam distillation process, the product was collected and separated using separatory funnel. The essential oils settled at the bottom layer of the separatory funnel and were separated several times until no oil was left in the separatory funnel. 


\section{Soxhlet extraction method}

$100 \mathrm{~g}$ of cinnamon stick were mashed into smaller pieces and placed inside a thimble made from thick filter paper, which was then loaded into the main chamber of the Soxhlet extractor. The extraction solvent used was ethanol. The solvent was heated to reflux at temperature above $100^{\circ} \mathrm{C}$ for 5 and 10 hours. After the extraction, the products were collected and purified using rotary evaporator at fixed temperature $50^{\circ} \mathrm{C}$. After rotovap, the samples were left under fume hood for one hour to make sure all the ethanol left in the oil crude was completely vaporized to the environment.

\section{Test for active compound using HPLC}

The active compound in cinnamon, cinnamaldehyde was tested using High Performance Liquid Chromatography (HPLC). The HPLC was run using a reversed-phase $\mathrm{C} 18$ column. The mobile phase comprising a mixture of methanolacetonitrile-water in volume ratio of 35:20:45 was delivered at a flow rate of $1.0 \mathrm{~cm}^{3} / \mathrm{min}$, and the detection for all samples to detect cinnamaldehyde was done at $221 \mathrm{~nm}$. Time used for the process was 20 min with temperature $38^{\circ} \mathrm{C}$. The volume injection for each sample was $50 \mu l$.

The water used was dehydrogenized water $\left(\mathrm{dH}_{2} \mathrm{O}\right)$. The mobile phase was chosen based on the experiment done by A. Gursale et al. (2010) where it showed successful result when comparing the cinnamaldehyde standard. $10 \mu \mathrm{g}$ of essential oil samples were diluted in $10 \mathrm{ml}$ methanol for all four samples used for HPLC ${ }^{8}$. The standard used was 95\% pure procured from Sigma Aldrich.

\section{Test for antimicrobial activity}

For the antimicrobial test, four different types of bacteria were used to determine the activities of the extracted cinnamon oil. One bacterium, Bacillus subtilis s.p. was gram positive type and another bacterium, Escherichia coli was gram negative type. The other two bacteria were unknown bacteria with unknown characteristics. The bacteria broth was prepared by culturing the bacteria in nutrient broth. The bacteria were incubated in oven for 48 hours at $37^{\circ} \mathrm{C}$ to ensure well growth of the bacteria colony.

The assays to inactivate the E. coli were carried out using the cinnamon oil extracted using steam distillation. The antibacterial activity of the essential oil was tested using disc agar diffusion method $^{8}$. Nutrient agar plates were swabbed with respective broth cultures of the organisms. Each sterile filter paper disc was impregnated with $10 \mu \mathrm{l}$ oil. The paper discs were then transferred onto the agar plate and incubated for 24 hours at $37^{\circ} \mathrm{C}$. All the process was carried out under laminar flow hood.

The antimicrobial activity was evaluated by measuring the inhibition zones expressed in millimeters $(\mathrm{mm})$ of inhibition against the tested organism ${ }^{8}$. The inhibition zone was measured using ruler and recorded for statistical analysis.

\section{RESULTS AND DISCUSSION}

\section{Steam distillation extraction}

Steam distillation process required water as the solvent which produced less harmful product and did not cause irritation. It also did not produce harmful vapor when it was released to the environment. Figure 1 showed the amount of oil extracted using steam distillation and Soxhlet extraction methods. The product extracted with steam distillation was less than the product extracted with Soxhlet extraction. This was because the temperature used for steam distillation was lower than Soxhlet extraction's. Higher temperature caused the solvent to evaporate faster. Soxhlet extraction used ethanol as the solvent which had lower boiling point than water and ethanol was a volatile substance.

Since the product was oil, some of it stuck to the collection jar during extraction and some was stuck to the separatory funnel during the separation of the oil from water. Oil has high viscosity, so some

Table 1: HPLC conditions

Analysis of Cinnamaldehyde in ethanol extract

\begin{tabular}{ll}
\hline Column & Reversed-phase C18 \\
Injection volume $(\mu \mathrm{l})$ & 50 \\
Mobile phase; ratio & Methanol-Acetonitrile- \\
& Water; 35:20:45 \\
Flow rate $\left(\mathrm{cm}^{3} / \mathrm{min}\right)$ & 1.0 \\
Wavelength $(\mathrm{nm})$ & 221 \\
Duration $(\min )$ & 20 \\
Temperature $\left({ }^{\circ} \mathrm{C}\right)$ & 38 \\
\hline
\end{tabular}


of the oil stuck inside the instruments.

Based from Figure 1, the results showed that the oil extracted for five hours was $0.914 \mathrm{~g}$ compared to $1.538 \mathrm{~g}$ from the ten hour extraction. The essential oils collected will be in higher quantity if the time used for extraction was longer.
During the extraction, the temperature must be controlled so that it will not rise above $100^{\circ} \mathrm{C}$. If the temperature was too high, the water from the round bottom flask will rise and enter the cooling tube and the collector flask. This will damage the product that was already extracted and the distillation process needs to be rerun.

Table 2: Comparison between standard and samples

\begin{tabular}{lccc}
\hline Sample & Experiment time (h) & Peak area \% & Retention time (min) \\
\hline Standard & - & 96.078 & 6.475 \\
Steam distillation & 5 & 94.728 & 6.371 \\
& 10 & 94.747 & 6.375 \\
Soxhlet extraction & 5 & 73.161 & 6.556 \\
& 10 & 62.737 & 6.503 \\
\hline
\end{tabular}

Table 3: Clear zones for each paper disc

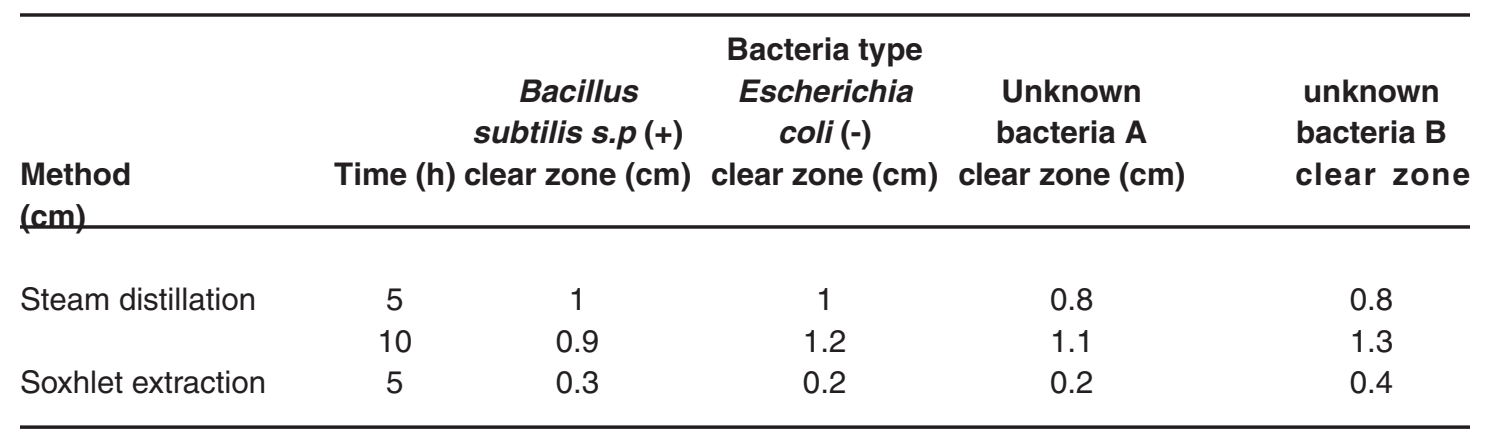

Table 4: Data analysis for clear zones formed

\begin{tabular}{lcccc}
\hline Summary & Count & Sum & Average & Variance \\
\hline Row 1 & 4 & 3.6 & 0.9 & 0.013333 \\
Row 2 & 4 & 4.5 & 1.125 & 0.029167 \\
Row 3 & 4 & 1.1 & 0.275 & 0.009167 \\
Row 4 & 4 & 1.3 & 0.325 & 0.015833 \\
Column 1 & 4 & 2.5 & 0.625 & 0.1425 \\
Column 2 & 4 & 2.6 & 0.65 & 0.276667 \\
Column 3 & 4 & 2.4 & 0.6 & 0.18 \\
Column 4 & 4 & 3 & 0.75 & 0.163333 \\
\hline
\end{tabular}

\begin{tabular}{lllllll}
\hline $\begin{array}{l}\text { ANOVA } \\
\text { Source of Variation }\end{array}$ & SS & df & MS & F & P-value & F crit \\
\hline Rows & 2.136875 & 3 & 0.712292 & 42.56017 & $1.21384 \mathrm{E}-05$ & 3.862548 \\
Columns & 0.051875 & 3 & 0.017292 & 1.033195 & 0.423271686 & 3.862548 \\
Error & 0.150625 & 9 & 0.016736 & & & \\
Total & 2.339375 & 15 & & & & \\
\hline
\end{tabular}


The oil collected was separated using separatory funnel which can be used to separate two layers of immiscible liquids such as water and oil. Essential oil from cinnamon has higher density than water so they will sink at the bottom of the separatory funnel. Some of the oil did not sink and formed oil bubble at the top and middle of the water later. Wait for a while to let the oil bubble sink and the oil at the bottom will be collected. The process of separating the oil will run several times until no oil can be separate anymore.

\section{Soxhlet extraction}

The process of Soxhlet extraction used ethanol as the solvent since the chemical was more effective than water for extraction. Ethanol was less dangerous compared to other extraction solvent such as methanol, hexane and chloroform. The experiment was run outside the fume hood since the vapor was not harmful to the environment. Acetone was also suitable for use in the extraction but it produced stingy smell compared to ethanol which was less smelly.

Table 5: Data analysis for steam distillation

\begin{tabular}{|c|c|c|c|c|c|}
\hline Summary & Count & Sum & Average & Variance & \\
\hline Row 1 & 4 & 3.6 & 0.9 & 0.013333 & \\
\hline Row 2 & 4 & 4.5 & 1.125 & 0.029167 & \\
\hline Column 1 & 2 & 1.9 & 0.95 & 0.005 & \\
\hline Column 2 & 2 & 2.2 & 1.1 & 0.02 & \\
\hline Column 3 & 2 & 1.9 & 0.95 & 0.045 & \\
\hline Column 4 & 2 & 2.1 & 1.05 & 0.125 & \\
\hline SS & df & MS & $\mathbf{F}$ & P-value & F crit \\
\hline 0.10125 & 1 & 0.10125 & 3.24 & 0.16968 & 10.12796 \\
\hline 0.03375 & 3 & 0.01125 & 0.36 & 0.788128 & 9.276628 \\
\hline 0.09375 & 3 & 0.03125 & & & \\
\hline 0.22875 & 7 & & & & \\
\hline
\end{tabular}

Table 6: Data analysis for Soxhlet extraction

\begin{tabular}{lcccc}
\hline Summary & Count & Sum & Average & Variance \\
\hline Row 1 & 4 & 1.1 & 0.275 & 0.009167 \\
Row 2 & 4 & 1.3 & 0.325 & 0.015833 \\
Column 1 & 2 & 0.6 & 0.3 & 0 \\
Column 2 & 2 & 0.4 & 0.2 & 0 \\
Column 3 & 2 & 0.5 & 0.25 & 0.005 \\
Column 4 & 2 & 0.9 & 0.45 & 0.005 \\
\hline
\end{tabular}

\begin{tabular}{lllllll}
\hline $\begin{array}{llllll}\text { ANOVA } \\
\text { Source of Variation }\end{array}$ & SS & df & MS & F & P-value & F crit \\
\hline Rows & 0.005 & 1 & 0.005 & 3 & 0.18169 & 10.12796 \\
Columns & 0.07 & 3 & 0.023333 & 14 & 0.028631 & 9.276628 \\
Error & 0.005 & 3 & 0.001667 & & & \\
Total & 0.08 & 7 & & & & \\
\hline
\end{tabular}


The products were collected in round bottom flask and purified using rotary evaporator. Rotary evaporator distilled all the ethanol and the oil was left in crude form. The crude oil was greasy and brown in color. The time needed for 5 hour extraction sample to be purified was 42 minutes while the 10 hour extraction sample took 28 minutes. The time for 10 hour extraction sample to be purified was shorter since it contained higher extracted oil content than the sample extracted for 5 hours. The ethanol volume was also less in the mixture of 10 hour extract sample which also shorten the time needed to rotovap.

Based from Figure 1, the oil collected for 5 hour extraction was $5.785 \mathrm{~g}$ and for the 10 hour extraction was $6.836 \mathrm{~g}$. This showed that the longer the extraction process, the higher the volume of the oil collected.

Table 7: Data analysis for 5 hour extraction using steam distillation and Soxhlet extraction

\begin{tabular}{lcccc}
\hline Summary & Count & Sum & Average & Variance \\
\hline Row 1 & 4 & 3.6 & 0.9 & 0.013333 \\
Row 2 & 4 & 1.1 & 0.275 & 0.009167 \\
Column 1 & 2 & 1.3 & 0.65 & 0.245 \\
Column 2 & 2 & 1.2 & 0.6 & 0.32 \\
Column 3 & 2 & 1 & 0.5 & 0.18 \\
Column 4 & 2 & 1.2 & 0.6 & 0.08 \\
\hline
\end{tabular}

\begin{tabular}{lllllll}
\hline $\begin{array}{l}\text { ANOVA } \\
\text { Source of Variation }\end{array}$ & SS & df & MS & F & P-value & F crit \\
\hline Rows & 0.78125 & 1 & 0.78125 & 53.57143 & 0.005268 & 10.12796 \\
Columns & 0.02375 & 3 & 0.007917 & 0.542857 & 0.685831 & 9.276628 \\
Error & 0.04375 & 3 & 0.014583 & & & \\
Total & 0.84875 & 7 & & & & \\
\hline
\end{tabular}

Table 8: Data analysis for 10 hour extraction using steam distillation and Soxhlet extraction

\begin{tabular}{lcccc}
\hline Summary & Count & Sum & Average & Variance \\
\hline Row 1 & 4 & 4.5 & 1.125 & 0.029167 \\
Row 2 & 4 & 1.3 & 0.325 & 0.015833 \\
Column 1 & 2 & 1.2 & 0.6 & 0.18 \\
Column 2 & 2 & 1.4 & 0.7 & 0.5 \\
Column 3 & 2 & 1.4 & 0.7 & 0.32 \\
Column 4 & 2 & 1.8 & 0.9 & 0.32 \\
\hline
\end{tabular}

\begin{tabular}{lllllll}
\hline $\begin{array}{l}\text { ANOVA } \\
\text { Source of Variation }\end{array}$ & SS & df & MS & F & P-value & F crit \\
\hline Rows & 1.28 & 1 & 1.28 & 96 & 0.00226 & 10.12796 \\
Columns & 0.095 & 3 & 0.031667 & 2.375 & 0.248001 & 9.276628 \\
Error & 0.04 & 3 & 0.013333 & & & \\
Total & 1.415 & 7 & & & & \\
\hline
\end{tabular}


Determination of active compound using HPLC

The HPLC was set at the conditions as shown in Table 1. Figure 2 showed the chromatogram of the standard cinnamaldehyde. The peak of the retention time for the standard was 6.475 and the peak area percentage was $96.078 \%$.

Figure 3 showed the comparison between cinnamaldehyde peak area percentage for steam distillation and Soxhlet extraction. The percentage of the peak area indicated the amount of cinnamaldehyde present in the samples. By using the peak area percentage, comparisons can be made between the samples. The sample from 5 hour steam distillation showed peak area percentage of $94.728 \%$. The peak area percentage for the sample from 10 hour steam distillation was $94.747 \%$. This showed that the distillation done for 10 hours had higher percentage of cinnamaldehyde compared to distillation done for 5 hours. The percentages showed little differences since the percentages of cinnamaldehyde were already very high from both extraction times. The peak area percentage for 5 hour Soxhlet extraction was $73.16 \%$ while the 10 hour extraction was $62.737 \%$. This showed that the percentage of cinnamaldehyde in 10 hour extraction was lower than 5 hour extraction, which indicated that the shorter the extraction time, the higher the cinnamaldehyde content in the sample extracted. Based from Table 2, the retention time for the oil extracted with steam distillation for 5 hours was 6.371 minutes and 6.375 minutes for oil extracted for 10 hours. The retention times were almost similar to the retention time of the standard. This indicated that the retention times of the samples were correct and acceptable.

Whereas the retention time for 5 hour Soxhlet extraction sample was 6.556 minutes and for 10 hour extraction was 6.503 minutes. The retention times of both extracted samples were also close to the retention time of the standard. The standard served as a guideline to determine whether the sample tested gave out the right retention time during HPLC test. The peak area percentages varied between test samples. The standard sample produced high peak area percentage since the purity was 95\%. Samples from steam distillation also produced high percentage of peak areas, which also meant that they contained high amount of cinnamaldehyde. The samples from Soxhlet extraction showed lower percentages of peak areas, which meant that they contained less amount of cinnamaldehyde compared to steam distillation samples.

These also indicated that steam distillation was the most suitable method for extracting cinnamaldehyde. Cinnamaldehyde might have lost its composition due to high temperature in Soxhlet extraction process compared to steam distillation which used lower temperature.

\section{Antimicrobial test}

After 48 hours of incubation, the bacteria grew uniformly and the antimicrobial properties can be evaluated for each paper disc. The areas of the

Table 9: T-test analysis for 5 hour extraction

\begin{tabular}{lcccc}
\hline & \multicolumn{4}{c}{ One-Sample Statistics } \\
& N & Mean & Std. Deviation & Std.Error Mean \\
\hline Steam 5h & 4 & .9000 & .11547 & .05774 \\
Soxhlet 5h & 4 & .2750 & .09574 & .04787 \\
\hline
\end{tabular}

Table 10: T-test analysis for 10 hour extraction

\begin{tabular}{lcccc}
\hline & \multicolumn{3}{c}{ One-Sample Statistics } \\
& $\mathrm{N}$ & Mean & Std. Deviation & Std.Error Mean \\
\hline Steam 10h & 4 & 1.1250 & .17078 & .08539 \\
Soxhlet 10h & 4 & .3250 & .12583 & .06292 \\
\hline
\end{tabular}


clear zones for each paper disc were measured with a ruler. The clear zones were bigger since pure oil without dilution was used. This showed that all the extracted samples have antimicrobial properties. The clear zone was observed by measuring the distance between the paper disc and the nearest bacteria population.

From Table 3, all paper discs showed antimicrobial properties against the bacteria since there were clear zones formed around them. This indicated that cinnamon has good antimicrobial properties and can be used in antiseptic production. Cinnamaldehyde was the main compound in the extracted cinnamon essential oil, thus it was the major component in the antimicrobial properties. Based from Figure 4, the line graph showed that the antimicrobial properties of the oil extracted from steam distillation was higher than the oil extracted from Soxhlet extraction since the clear zones were wider. The extraction time also contributed to the differences in the clear zone widths. Clear zones from 10 hour extraction samples were wider than the clear zones from 5 hour extraction samples. This applied for both steam distillation and Soxhlet extraction.

\section{Statistical analysis}

Statistical analysis was done to test whether the result was significant or not significant. The confidence level used was $99 \%$ where the data was significant if the $p$ value was $\leq 0.01$. The data was not significant if the $p$ value was $\geq 0.01$. Significant data means that the data collected is correct and suitable for the study. The statistical analysis was calculated using two-way anova since there were two manipulated variables which were the durations for each extraction method and the four different types of bacteria used in the test. The two-ways anova was made as shown in Table 4.

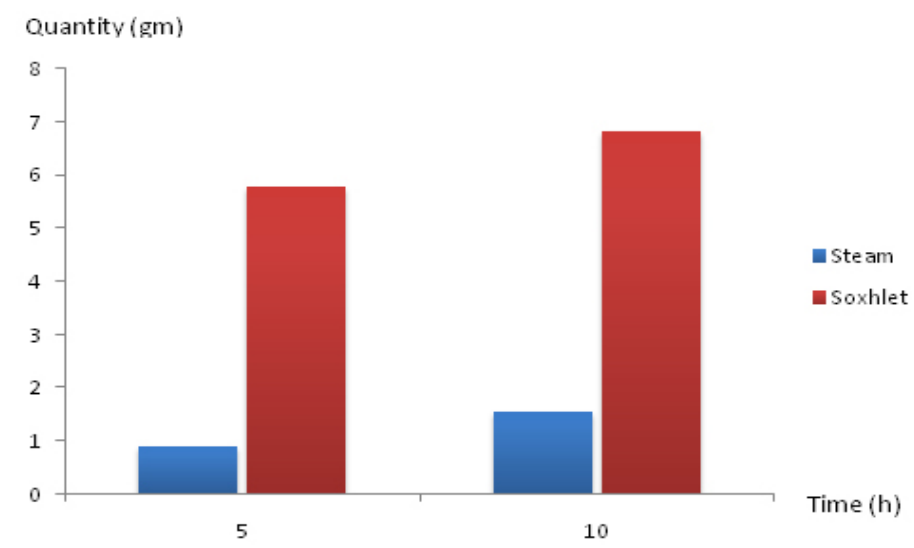

Fig. 1: Graph of the quantity of the extracted oil

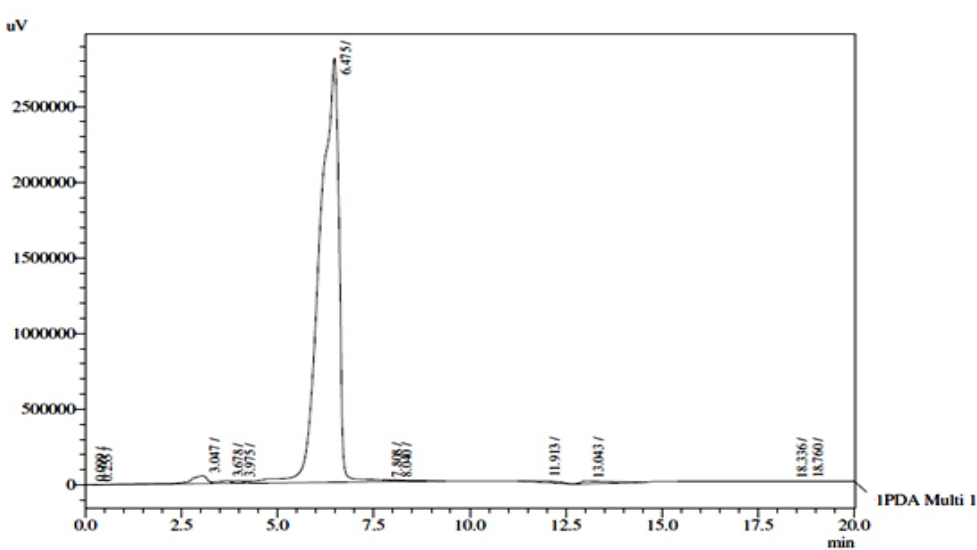

Fig. 2: Chromatogram of standard cinnamaldehyde 
All the data collected was compared to determine the significance between the methods, times, and the clear zones on the culture bacteria as shown in Table 4. The $p$ value for the rows was $1.21384 \times 10^{-5}(\leq 0.01)$. This meant that the value was significant and the rows can be compared. The rows represented the time for the both steam distillation and Soxhlet extraction. The time between the methods of extraction was significant to study. The column $p$ value was $0.423271686(\leq 0.01)$. The columns that represented the clear zones formed for each bacteria plate were not significant since each bacterium has different antimicrobial properties considering the different extraction methods and durations used.

Table 5 showed the statistical analysis of steam distillation extraction. The $p$ value for the rows was $0.16968(\geq 0.01)$ and was not significant.
The rows represented the time of 5 hour and 10 hour extraction, so this mean the times were not significant to be compared since different time of extraction produced different amount of oil. The $p$ value for columns was $0.788128(\geq 0.01)$ where the value was not significant. The columns represented the clear zones formed for each disc from steam distillation. The clear zone was not significant to be compared since different bacteria had different levels of antibiotic resistance.

Table 6 showed the statistical analysis for Soxhlet extraction. The $p$ value for the rows was $0.18169(\geq 0.01)$ and was not significant. The rows represented the 5 hour and 10 hour extraction time, meaning that the times were not significant to be compared since different extraction times produced different amount of oil. The $p$ value for columns was $0.028631(\geq 0.01)$ and was not significant since

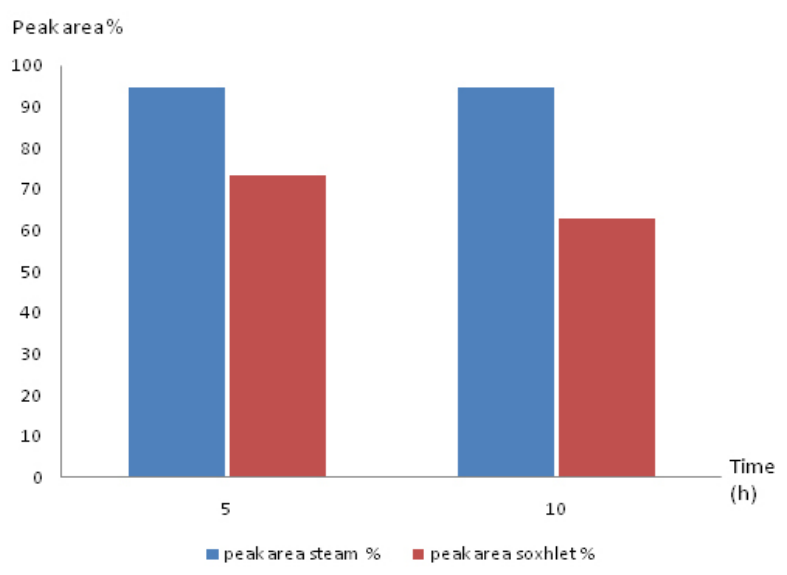

Fig. 3: Graph of peak area percentages from steam distillation and Soxhlet extraction

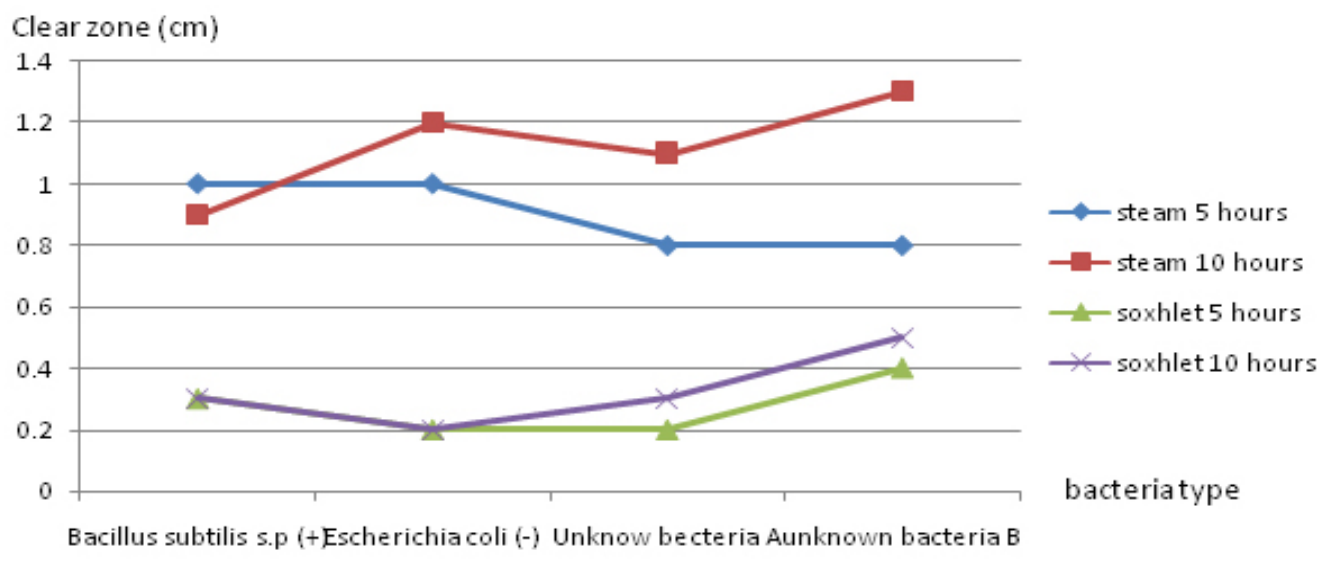

Fig. 4: Line graph of clear zones formed from each disc paper 
different bacteria had different antibiotic resistance. Table 7 showed statistical analysis of 5 hour extraction for both steam distillation and Soxhlet extraction methods. The $p$ value of the rows was $0.005268(\leq 0.01)$ and the value was significant. The rows represented 5 hour extraction for both steam distillation and Soxhlet extraction. The values can be compared since same time was used which was 5 hours. The $p$ value for column was $0.685831(\geq 0.01)$. This meant that the value was not significant. The columns represented the clear zones formed from each disc and were not significant to compare since the clear zones for each extraction method had large differences.

The statistical analysis of 10 hour extraction using both steam distillation and Soxhlet extraction methods was shown in Table 8. The $p$ value for rows was $0.00226(\leq 0.01)$. This meant the value was significant. The rows represented the data of 10 hour extraction from both steam distillation and Soxhlet extraction. The values can be compared since same time was used, which was 10 hours. The $p$ value for columns was $0.248001(\geq 0.01)$. This meant the value was not significant. The columns represented the clear zones formed for each paper disc and were not significant to be compared since the clear zones formed from each extraction method had large differences.

\section{T-test analysis}

T-test was to determine whether two samples were likely to have come from the same two underlying populations that have the same mean. From T-test, the mean, standard deviation and standard error mean were calculated. The standard error mean determined the accuracy of the reading. The lower the standard error mean, the more accurate the reading. Based from Table 9, the T-test showed that the mean for 5 hour extraction was 0.9 . This showed the average clear zone for 5 hour steam distillation sample was larger compared to 5 hour Soxhlet extraction sample's where the mean was 0.275 . The standard error of 5 hour steam distillation was 0.05774 and for Soxhlet extraction's was 0.04787 . Both of the standard errors were small because most of the clear zones formed were equal in area size for both methods. Table 10 showed that the mean for 10 hour steam distillation was 1.1250 and 0.3250 for Soxhlet extraction. The mean for steam distillation was larger since the clear zones formed was larger than Soxhlet extraction's. The mean for 10 hour extraction for both steam distillation and Soxhlet extraction were larger than their mean for 5 hour extraction. This showed that 10 hours of extraction was more suitable to use in the experiment because it produced more cinnamaldehyde compared to 5 hour extraction.

The standard error mean for 10 hour steam distillation was 0.08539 and 0.06292 for 10 hour Soxhlet extraction. Both of the standard error mean were small since the clear zones formed were almost equal in area size.

\section{CONCLUSION}

Extraction of essential oil from Cinnamomum zeylanicum can be done using two different methods with optimum essential oil yield, which were steam distillation and Soxhlet extraction. Heat was applied in both methods for faster extraction compared to other methods which did not require heat but took a lot of time instead such as solvent extraction. In steam distillation, the solvent was water so that the essential oil produced was pure without being affected by the solvent. Soxhlet extraction used ethanol as the solvent since the compound was more effective than water for extraction. Ethanol was less dangerous compared to other extraction solvent such as methanol, hexane and chloroform. There are many other extraction methods that can be used to extract the essential oil from cinnamon such as solvent extraction. Different methods will produce different amount and quality of essential oil.

From the HPLC test results, the extracted products showed that cinnamon contained high amount of cinnamaldehyde from both extraction methods which were $94.728 \%$ from 5 hour steam distillation, $94.747 \%$ from 10 hour steam distillation, $73.16 \%$ from 5 hour Soxhlet extraction, and $62.737 \%$ from 10 hour Soxhlet extraction.

The antimicrobial tests to determine the antimicrobial properties present in the extracted cinnamon oil showed the formation of clear zones around all paper discs, which meant that all of the oil extracts from different extraction methods and durations had antimicrobial properties that inhibited 
the growth of the selected bacteria. The antimicrobial tests were only tested on four different types of bacteria. The number and types of bacteria can be varied more since different bacteria have different antibiotic resistance. Other than the antimicrobial test, there are also many other tests that can be done to test the activities of the active compound such as anti-oxidant test.

\section{REFERENCES}

1. Elumalai, S., Kesavan, R., Ramganesh, S., \& Murugasen, R., Isolation, purification and identification of the antidiabetic components from Cinnamomum zeylanicum and Cinnamomum cassia bark oil extracts. Current Botany, 2(2): 12-17 (2011).

2. Schmidt, E., Jirovetz, L., Buchbauer, G., Eller, G. A., Stoilova, I., Krastanov, A., et al., Composition and Antioxidant Activities of the Essential Oil of Cinnamon (Cinnamomum zeylanicum Blume) Leaves from Sri Lanka. Jeobp, 9(2): 170-182 (2008).

3. Faix, S., Faixová, Z., Plachá, I., \& Koppel, J., Effect of Cinnamomum zeylanicum Essential Oil on Antioxidative Status in Broiler Chickens. Thai Herbal Pharmacopoeia, 1995, Volume I. Prachachon Co., Ltd., pp.38 (2009).

4. Roy, H. J., Lundy, S., Eriksen, C., \& Kalicki, B., Pennington Nutrition Series, 3: 56-74 (2009).

5. Govender, H., A Comparative Study of Solvent Extraction, Soxhlet Extraction, Steam Distillation, Headspace Analysis and Headspace Solid Phase Microextraction for the Extraction of Volatile Terpenoid
Compounds in the Curry Leaf Plant. B. Sc. Thesis. University of KwaZulu-Natal, Durban (2010).

6. M. Agarwal, A. Kumar, R. Gupta and S. Upadhyaya, Orient J. Chem., 28(2): 993-998 (2012).

7. D. Prasad and S.P. Sati, Orient J. Chem., 28(1): 591-593 (2012).

8. El-Baroty, G.S., Abd El-Baky, H.H., Farag, R.S., Saleh, M.A., Characterization of antioxidant and antimicrobial compounds of cinnamon and ginger essential oils. African Journal of Biochemistry Research, 4(6): 167174 (2010).

9. Senhaji, O., Faid, M., \& Kalalou, I., Inactivation of Escherichia coli O157:H7 by Essential Oil from Cinnamomum zeylanicum. Brazilian Journal of Infectious Diseases, 11(2): 234236 (2007).

10. Gursale, A., Dighe, V., \& Parekh, G., Simultaneous Quantitative Determination of Cinnamaldehyde and Methyl Eugenol from Stem Bark of Cinnamomum zeylanicum Blume Using RP-HPLC. Journal of Chromatographic Science, 48: 59-62 (2010). 